\title{
Structurally Diverse Bench-Stable Nickel(0) Pre-Catalysts: A Practical Toolkit for In Situ Ligation Protocols
}

Van T. Tran, ${ }^{\dagger} \S$ Nana Kim, ${ }^{\dagger} \S$ Camille Z. Rubel, ${ }^{\dagger}$ Xiangyu Wu, ${ }^{\ddagger}$ Taeho Kang, ${ }^{\dagger}$ Tanner C. Jankins, ${ }^{\dagger}$ Zi-Qi Li, ${ }^{\dagger}$ Matthew V. Joannou,

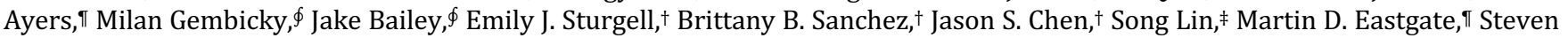
R. Wisniewski, $\Uparrow$ Keary M. Englet,*

†Department of Chemistry, The Scripps Research Institute, 10550 North Torrey Pines Road, La Jolla, California 92037, United States

¥Department of Chemistry and Chemical Biology, Cornell University, Ithaca, New York 14853, United States

"Chemical Process Development, Bristol Myers Squibb, 1 Squibb Drive, New Brunswick, New Jersey 08903, United States

$\oint$ Department of Chemistry and Biochemistry, University of California, San Diego, 9500 Gilman Drive, La Jolla, California 92093, United States

§Authors contributed equally.

KEYWORDS: nickel, pre-catalyst, ligand design, cross-coupling

\begin{abstract}
A flurry of recent research has centered on harnessing the power of nickel catalysis in organic synthesis. These efforts have been bolstered by contemporaneous synthesis, characterization, and optimization of well-defined nickel (pre)catalysts with diverse structure and reactivity. In this report, we present the development of ten different bench-stable, 18-electron, formally zero-valent nickel-olefin complexes that are shown to be competent pre-catalysts in various reactions. Our investigation includes preparations of novel, bench stable Ni(COD)(L) complexes, in which L = quinone, cyclopentadienone, thiophene-S-oxide, and fulvene. Characterization by a battery of techniques, including NMR, IR, single-crystal X-ray diffraction, cyclic voltammetry, thermogravimetric analysis, and natural bond orbital analysis sheds light on the structure, bonding, and properties of these complexes. Kinetic profiling across a series of representative reactions reveals reactivity differences that stem from the nature of the ancillary ligand, underscoring the complementary relationships between each pre-catalyst within this toolkit.
\end{abstract}

Introduction

Nickel catalysis research has witnessed a surge of interest in recent years. Various synthetic transformations capitalize on nickel's unique combination of properties: namely, its ability to undergo facile oxidative addition, its capacity to maneuver through oxidation states via single-electron transfer processes, and the relatively sluggish nature of $\beta$ hydride elimination from alkylnickel intermediates. ${ }^{1-3}$ Moreover, the lower economic and environmental costs of nickel compared to precious metals, such as palladium, iridium, and ruthenium, drive its increasingly widespread adoption. $^{4-6}$

As the use of nickel-catalyzed transformations has increased, so too has reliance upon the various nickel pre-catalysts that are available to practitioners. Prominently used nickel pre-catalysts can be categorized based on the metal's oxidation state: $\mathrm{Ni}(\mathrm{II})$ species, such as simple nickel halide salts as well as aryl and allyl oxidative addition complexes, and formally $\mathrm{Ni}(0)$ species, including those that are pre-ligated with phosphine, $\mathrm{N}$-heterocyclic carbene (NHC), or nitrogen-based ligands, and olefin-bound variants used in insitu ligation protocols. ${ }^{7}$

Comparing $\mathrm{Ni}(\mathrm{II})$ and $\mathrm{Ni}(0)$ pre-catalysts, $\mathrm{Ni}(0)$ complexes offer the advantage of being able to directly enter the catalytic cycle through ligand exchange, without the need to undergo other elementary steps. While pre-ligated $\mathrm{Ni}(0)$ complexes, such as Montgomery's Ni(NHC)(EDO) $($ EDO = electron-deficient olefin) series, have proven highly enabling, ${ }^{8} \mathrm{Ni}(\mathrm{COD})_{2}$ (COD = 1,5-cyclooctadiene) has generally dominated as the standard $\mathrm{Ni}(0)$ pre-catalyst due to the comparative lability of its COD ligands. This is especially true in the early stages of reaction optimization, owing to its high commercial availability and ability to coordinate a wide variety of ligands in situ. Nevertheless, its extreme sensitivity to oxygen, moisture, various solvents, and even moderate heat (Figure $1 \mathrm{~A})^{9-11}$ necessitates handling in an inert atmosphere and long-term storage at low temperature. ${ }^{12}$ This, in turn, has hindered broad adoption of catalytic reactions that rely on $\mathrm{Ni}(\mathrm{COD})_{2}$ in many settings, particularly in pharmaceutical process development.

Bench-stable complexes that are functionally equivalent to $\mathrm{Ni}(\mathrm{COD})_{2}$ for in situ ligation protocols are thus attractive targets for organometallic synthesis. To this end, our lab identified $\mathrm{Ni}(\mathrm{COD})(\mathrm{DQ})$ (DQ = duroquinone), ${ }^{13}$ originally prepared by Schrauzer in $1962,{ }^{14}$ as an extraordinarily stable and versatile pre-catalyst for a number of important reactions, such as Suzuki-Miyaura cross-coupling, BuchwaldHartwig amination, and Miyaura borylation. ${ }^{13,15}$ However, $\mathrm{Ni}(\mathrm{COD})$ (DQ) was not always a suitable replacement for $\mathrm{Ni}(\mathrm{COD})_{2}{ }^{16}$ as some reactions required longer reaction 
A. Traditional $\mathrm{Ni}(0)$ precatalysts

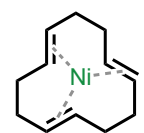

$\mathrm{Ni}(\mathrm{cdt})$

$16 \mathrm{e}^{-}$

B. Recent relevant precedents

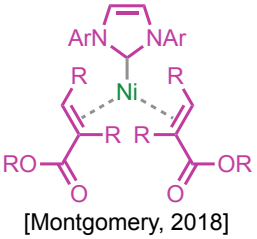

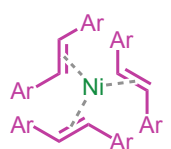

[Cornella, 2020]

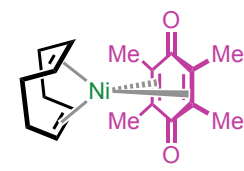

[Engle, 2020]
C. This work

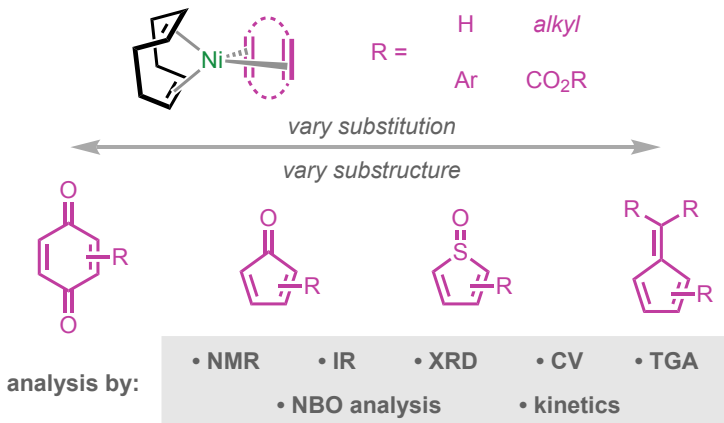

Figure 1. A. Traditionally used olefin-bound nickel(0) precatalysts $\mathrm{Ni}(\mathrm{cdt})$ and $\mathrm{Ni}(\mathrm{COD})_{2}$ which are air and temperature sensitive. cdt $=(1 E, 5 E, 9 E)$-cyclododecatriene, $\mathrm{COD}=1,5$-cyclooctadiene. $\mathrm{B}$. Recent precedents for bench-stable low-valent nickel complexes. C. This work of developing low-valent bench-stable nickel complexes with various quinone, cyclopentadienone, thiophene sulfoxide, and fulvene ligands.

times or did not proceed altogether, ${ }^{17}$ a limitation that we attribute to the low substitutional lability of DQ, which is especially problematic with weakly $\sigma$-donating ligands and points to the need for new pre-catalyst designs. In parallel to our work, Cornella and coworkers disclosed a series of 16-electron formally $\mathrm{Ni}(0)$-tris(stilbene) [Ni(stb) 3$]$ complexes that function as bench-stable pre-catalysts for a variety of transformations. ${ }^{18}$ Recently the Cornella lab further demonstrated that modification of the substituents on the stilbene can lead to improved reactivity and stability. ${ }^{19}$

In seeking to address the shortcomings of $\mathrm{Ni}(\mathrm{COD})(\mathrm{DQ})$ and expand the reach of bench-stable 18-electron $\mathrm{Ni}(0)$ pre-catalysts, we hypothesized that modifying the Ni(COD)(L) architecture to new ligand scaffolds with varied coordination strength would unlock new reactivity. Herein, we identify four tunable ligand families, namely quinones, cyclopentadienones, thiophene- $S$-oxides, and fulvenes, that give rise to bench-stable Ni(COD)(L) complexes, which in turn function as an effective pre-catalyst toolkit in various transformations (Figure 1C). Using an array of analytical techniques, the structural, electronic, and physical properties of these pre-catalysts were systematically characterized, and their catalytic performance was compared across several $\mathrm{C}-\mathrm{C}$ and $\mathrm{C}-\mathrm{N}$ bond-forming reactions from the literature that employ a variety of ligands, solvents, and bases. The profound effect of the supporting ligand in modulating the properties and reactivity across this series underscores the value of a structurally diverse library of robust and conveniently available $\mathrm{Ni}(0)$ pre-catalysts for reaction discovery and optimization.

\section{Results and Discussion}

1. Ligand screening and synthesis

To begin this study, we developed a standardized protocol for rapidly assessing potential ligand candidates. This workflow evaluated ligands based on two criteria: (1) first, whether they formed a well-defined $\mathrm{Ni}(\mathrm{COD})(\mathrm{L})$ complex, and (2) second, whether the resulting complex was stable to demanding work-up/purification procedures on the bench top. To these ends, ligands of interest were combined with $\mathrm{Ni}(\mathrm{COD})_{2}$ in 1:1 molar ratio in $\mathrm{C}_{6} \mathrm{D}_{6}$ under inert atmosphere, ${ }^{20}$ and the resulting mixture was analyzed by ${ }^{1} \mathrm{H}$ NMR (Figure 2A, see SI for details). The appearance of free COD along with new diastereotopic alkenyl ${ }^{1} \mathrm{H}$ resonances from the remaining Ni-bound COD ligand indicated formation of a well-defined $\mathrm{Ni}(\mathrm{COD})(\mathrm{L})$ complex, whereas ineffective ligands led to unreacted starting materials, intractable mixtures, complete decomposition, or unassignable broad peaks. ${ }^{21}$ Successful complexation was typically also accompanied by a color change of the homogenous reaction mixture to dark red/purple. In contrast, the physical appearance of unpromising experiments varied dramatically depending on the ligand employed. Experiments showing evidence of $\mathrm{Ni}(\mathrm{COD})(\mathrm{L})$ formation were carried forward for preliminary stability assessment. Specifically, the crude reaction mixture was directly loaded onto a bed of silica gel under air, and elution with hexane/EtOAc was then attempted.

Utilizing this workflow, we screened 69 ligands spanning 13 structural classes (Figure 2B), and eventually identified four classes for further development (quinones, cyclopentadienones, thiophene- $S$-oxides, fulvenes), ultimately leading to the identification of the 10 stable nickel complexes shown in Figure 2C. Echoing earlier findings, ${ }^{19}$ one successful series is based on quinone ligands. While we have previously shown that $\mathrm{Ni}(\mathrm{COD})(\mathrm{DQ})(\mathbf{1}),{ }^{13}$ where the quinone bears tetramethyl substitution, is highly stable, unsubstituted benzoquinone (BQ) (L11) gives an intractable mixture, ${ }^{22}$ pointing to the importance of the substituents on the quinone. With this in mind, we investigated different substitution patterns and groups with varying steric and electronic properties. 2,6-Disubstituted quinones (L12) were found not to form isolable complexes, and removal of a methyl group from DQ, as seen in 2,3,6-trimethyl-1,4-benzoquinone (L13) led to an unstable complex. In contrast, we found that dialkyl substitution at the 2,5-positions, as in bis(tert-butyl) (L2) and bis(cyclohexyl) (L3) resulted in isolable, bench-stable complexes 2 and 3, respectively, as red-orange solids (Figure 2C). Interestingly, aryl (L14-L16) and fluoro (L17) substituents led to complete decomposition, irrespective of the substitutions on the aryl ring, presumably due to their stronger oxidizing ability. ${ }^{23}$ Broadly speaking, these empirical results reveal that $\mathrm{C}_{2}$-symmetric complexes containing alkyl-substituted quinone ligands are typically stable, reflecting an intricate interplay of redox behavior, steric hindrance, and symmetry of the quinone ligand. 


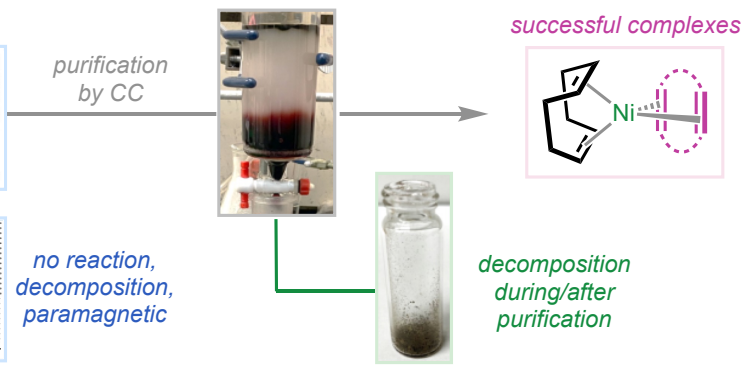

B. Selected examples of unsuccessful ligands<smiles>O=C1C=CC(=O)C=C1</smiles>

L11<smiles>CC(C)(C)C1=CC(=O)C=C(C(C)(C)C)C1=O</smiles>

L12<smiles>CC1=CC(=O)C(C)=C(C)C1=O</smiles>

L13<smiles>O=C1C=C(Pc2ccccc2)C(=O)C=C1P</smiles>

L14<smiles>COc1ccc(C2=CC(=O)C(Br)=CC2=O)cc1</smiles>

L15<smiles>O=C1C=C(c2ccc(C(F)(F)F)cc2)C(=O)C=C1[Te]</smiles>

L16<smiles>O=C1C(=O)C(F)=C(F)C(F)=C1F</smiles>

L17<smiles>CCC1=C(C(C)=O)C2C=CC1C2</smiles>

L18<smiles>CCC1=C(C(OC)OC)C2C=CC1C2</smiles>

L19

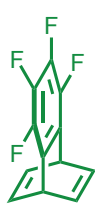

L20<smiles>O=C1C=CC(=O)C23CC12CC1C=CC3C1</smiles>

L21<smiles>CCOC(=O)C1=C2C(=C(CC)C1=O)c1cccc3cccc2c13</smiles>

L22<smiles>CCC1=C(c2ccccc2)C(c2ccccc2)=C(C(C)=O)C1=O</smiles>

L23<smiles>O=C1C(Br)=C(c2ccccc2)C(c2ccccc2)=C1C(=O)c1ccccc1</smiles>

L24<smiles>CCOC(=O)c1cocc1CC</smiles>

L25<smiles>FC(F)(F)c1ccc(-c2oc([Al])c(Br)c2Br)cc1</smiles>

L26<smiles></smiles>

L27<smiles>O=P1(c2ccccc2)C(P)=C(c2ccccc2)C(c2ccccc2)=C1c1ccccc1</smiles>

L28<smiles>c1ccc(-c2sc(-c3ccccc3)c(-c3ccccc3)c2-c2ccccc2)cc1</smiles>

L29<smiles>O=S1(=O)C(c2ccccc2)=C(c2ccccc2)C(c2ccccc2)=C1c1ccccc1</smiles>

L30<smiles>COc1ccc(C2=C([Al])C([Al])=C([Al])S2=O)cc1</smiles><smiles>CCC1=C(CC)S(=O)C(CC)=C1CC</smiles><smiles>C1=CC(=C(c2ccccc2)c2ccccc2)C=C1</smiles><smiles>C=C1C(c2ccccc2)=C(c2ccccc2)C(c2ccccc2)=C1c1ccccc1</smiles><smiles></smiles><smiles>N#CC(C#N)=C1C(c2ccccc2)=C(c2ccccc2)C(c2ccccc2)=C1c1ccccc1</smiles><smiles>CCc1cc2ccccc2cc(C(C)=O)c1=O</smiles>

\section{Successful complexes}

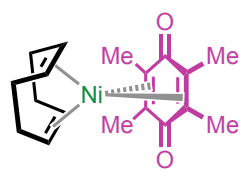

$1,79 \%$

$\mathrm{Ni}(\mathrm{COD}) \mathrm{DQ}$

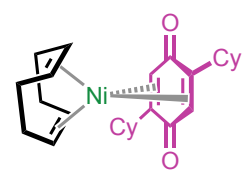

3, $84 \%$ $\mathrm{Ni}(\mathrm{COD}) \mathrm{BQ}^{\mathrm{Cy}}$

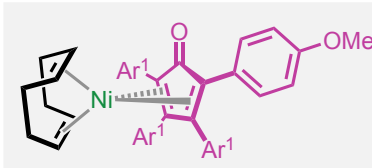

5, $91 \%$ $\mathrm{Ni}(\mathrm{COD}) \mathrm{CPD}^{\mathrm{OMe}}$

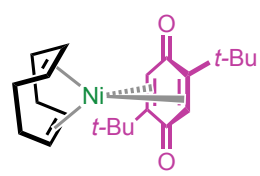

2, 93\%

$\mathrm{Ni}(\mathrm{COD}) \mathrm{BQ}^{\mathrm{tBu}}$

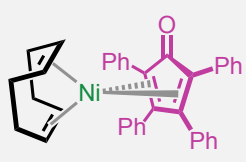

4, $>98 \%$ $\mathrm{Ni}(\mathrm{COD}) \mathrm{CPD}^{\mathrm{H}}$

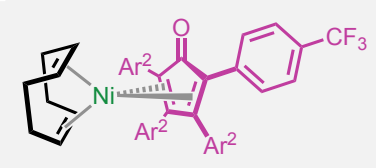

6, $87 \%$ $\mathrm{Ni}(\mathrm{COD}) \mathrm{CPD}^{\mathrm{CF} 3}$<smiles>O=S1C(P)=C(P(c2ccccc2)N2C3CCCC2CC3)C(c2ccccc2)=C1c1ccccc1</smiles>

7, $70 \%$ $\mathrm{Ni}(\mathrm{COD}) \mathrm{TO}^{\mathrm{H}}$

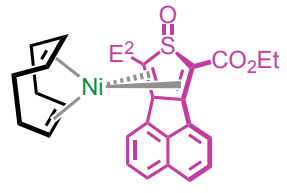

9, $46 \%$ $\mathrm{Ni}(\mathrm{COD}) \mathrm{TO}^{\mathrm{A}}$

Figure 2. A. Graphical depiction of workflow for ligand screening $(0.05 \mathrm{mmol})$ to form isolable, bench-stable, low-valent nickel complexes. B. Selected examples of unsuccessful ligands. Ligands that lead to no reaction, decomposition, and/or tentative formation of paramagnetic species are depicted in blue. Ligands that lead to formation of desired nickel complex by ${ }^{1} \mathrm{H}$ NMR where the resulting complexes were unstable to isolation attempts are depicted in green. C. Successfully synthesized bench-stable nickel complexes starting with 0.5 or $1.0 \mathrm{~g} \mathrm{Ni}(\mathrm{COD})_{2}$ and corresponding isolated yields. Shaded boxes separate four different classes of ligand substructures (quinone, cylopentadienone, thiophene sulfoxide, fulvene). See SI for reaction conditions and additional unsuccessful ligands. $\mathrm{Ar}^{1}=4-\mathrm{OMeC}_{6} \mathrm{H}_{5}, \mathrm{Ar}^{2}$ $=4-\mathrm{CF}_{3} \mathrm{C}_{6} \mathrm{H}_{5}, \mathrm{E}^{1}=\mathrm{CO}_{2} \mathrm{Me}, \mathrm{E}^{2}=\mathrm{CO}_{2} \mathrm{Et}$.

After gaining a better understanding of substituent effects on complexation of quinone-type ligands, we evaluated other ligand scaffolds. We tested various bidentate olefin ligands, including norbornadiene (L18) and [2.2.2]-bicylooctadienes $(\mathbf{L 1 9}, \mathbf{L 2 0})$ due to their precedented success as ligands in rhodium catalysis. ${ }^{24,} 25$ Surprisingly, although some of these gave the desired product, as detected by crude ${ }^{1} \mathrm{H}$ NMR and/or single-crystal X-ray diffraction, none were readily isolable on preparative scale or bench-stable in the solid state. Ligands in which the two olefins were 
farther apart (L21) also proved to be unsuccessful, despite precedents demonstrating their coordination to low-valent palladium. ${ }^{26}$

We noted that this lack of success may be due to a mismatch of the bite angle of the olefin in relation to the relatively small size of the nickel center. We thus focused our attention on ligands containing an embedded conjugated 1,3diene motif. We tested cyclopentadienones, reasoning that they might function analogously to quinones given their structural similarity. Notably, in 1986 Boleslawski and coworkers reported the synthesis and characterization of such a complex, $\mathrm{Ni}(\mathrm{COD})\left(\mathrm{CPD}^{\mathrm{H}}\right)(4) ;{ }^{27}$ however, its stability and catalytic reactivity have not been characterized to our knowledge. We were able to access $\mathrm{Ni}(\mathrm{COD})\left(\mathrm{CPD}^{\mathrm{H}}\right)(\mathbf{4})$ as a dark-purple solid in quantitative yield, finding it to be highly stable to air and moisture (Figure 2C). Other substituted tetraarylcyclopentadienone ligands with varied electronic properties, as exemplified by tetra(4-methoxyphenyl) and tetra(4-trifluoromethylphenyl) cyclopentadienone (L5 and L6, respectively), also coordinated cleanly. These ligands furnished the desired bench-stable nickel complexes $\mathbf{5}$ and $\mathbf{6}$ as dark solids. Although we had assumed that increasing the electron-deficient nature of the ligand may increase likelihood of complexation to electron-rich low-valent nickel, we instead observed that electron-withdrawing ester (L22, L23) and ketone (L24) substituents at the 2,5-positions of the cyclopentadienone scaffold resulted in no observable complex formation. We were eager to test alkyl substituted cyclopentadienones, but their propensity to dimerize immediately following their formation via the DielsAlder reaction precluded these efforts.

In testing other cyclic 1,3-dienes, we found furans (L25, L26), phospholes (L27, L28), thiophenes (L29), and thiophene sulfones (L30) to be ineffective at complexation. We had initially expected thiophene sulfones to be successful due to precedent that shows their ability to coordinate to low-valent iron and cobalt. ${ }^{28,}{ }^{29}$ However, tetraphenyl thiophene sulfone (L30) lead to decomposition of the ligand upon combination with $\mathrm{Ni}(\mathrm{COD})_{2}$. Instead, to our surprise, the corresponding tetraphenyl thiophene-S-oxide (L7) proved to be successful, resulting in bench-stable 18-electron complex 7 (Figure 2C). To the best of our knowledge, thiophene-S-oxide ligands have not previously been reported in complexation with nickel. Expanding on this unique result, we found that tetra(4-trifluoromethylphenyl) thiophene-S-oxide (L8) yielded the desired complex 8, and a 2,5-diester substituted thiophene-S-oxide (L9) yielded complex 9, in contrast to cyclopentadienone analogue L22. In another departure from trends observed with cyclopentadienone scaffolds, tetra(4-methoxyphenyl) thiophene-S-oxide (L31) did not produce an isolable nickel complex, which would have been analogous to complex $\mathbf{5}$. Tetraethyl thiophene-S-oxide (L32) proved to be equally unsuccessful. These results suggest that the cyclopentadienone series tolerates moderately electron-poor to electron-rich ligands, while electron-neutral or -deficient ligands are required for the thiophene-S-oxide series.

At this point, we questioned whether a double bond to an electron-withdrawing heteroatom, such as $\mathrm{C}=0$ and $\mathrm{S}=0$, is necessary, or if a suitably substituted $\mathrm{C}=\mathrm{C}$ bond could also function in an analogous fashion. Indeed, fulvene complex $\mathrm{Ni}(\mathrm{COD})(\mathbf{L 3 3})$ had been previously synthesized and characterized by Behrens and coworkers in 1982, though its stability and catalytic activity was not described in detail. ${ }^{30}$ Upon testing diphenylfulvene (L33), we indeed observed complexation by crude ${ }^{1} \mathrm{H}$ NMR, but the resulting material did not pass our stability test, suggesting it would be necessary to tune the fulvene scaffold to identify a stable variant. Therefore, we synthesized and tested a handful of analogs of the initial diphenylfulvene ligand. Electron-neutral, -donating, and -withdrawing substituents were generally unsuccessful (L34 \& L35, See SI for details), except for 6,6-dicyano substitution, which resulted in isolable complexes in some cases. Initially, we identified tetraphenyl-6,6-dicyano fulvene (L36) as a promising ligand but encountered reproducibility issues in the purification and long-term benchstability of the resulting complex. In an effort to improve these properties, we found that replacement of the phenyl groups at the 1- and 4-positions with less bulky methyl groups (L10) resulted in an isolable, bench-stable nickel fulvene complex 10 (Figure 2C). Lastly, ring expansion to a 7membered benzotropone motif, which contains two embedded 1,3-dienyl moieties (L37), resulted in an unstable complex.

\section{Synthesis and characterization}

Figure 2C summarizes successfully isolated and characterized bench-stable low-valent nickel complexes. While initial ligand screening experiments were performed on smallscale $(0.05 \mathrm{mmol})$, we found that complexes 1-10 could be conveniently prepared on gram scale via simple ligand exchange from $\mathrm{Ni}(\mathrm{COD})_{2}$ (see Table S1 in the Supporting Information for additional data). Alternatively, we developed a two-step telescoped sequence from $\mathrm{Ni}(\mathrm{acac})_{2}$, which is a more user-friendly and less expensive precursor compared with $\mathrm{Ni}(\mathrm{COD})_{2}$, and allows pre-catalyst synthesis without the use of a glovebox. As shown for two representative examples with commercially available ligands (L1 and L4), the desired complexes $\mathbf{1}$ and $\mathbf{4}$ were successfully prepared in good yield on gram scale by reduction of $\mathrm{Ni}(\text { acac) })_{2}$ with DIBAL-H (Figure 3 ) followed by solvent-swap and ligand introduction.

Complexes 1-10 were fully characterized by ${ }^{1} \mathrm{H}$ NMR, ${ }^{13} \mathrm{C}$ NMR, single-crystal X-ray diffraction, and IR. Additionally, for comparison, the free ligands were characterized using

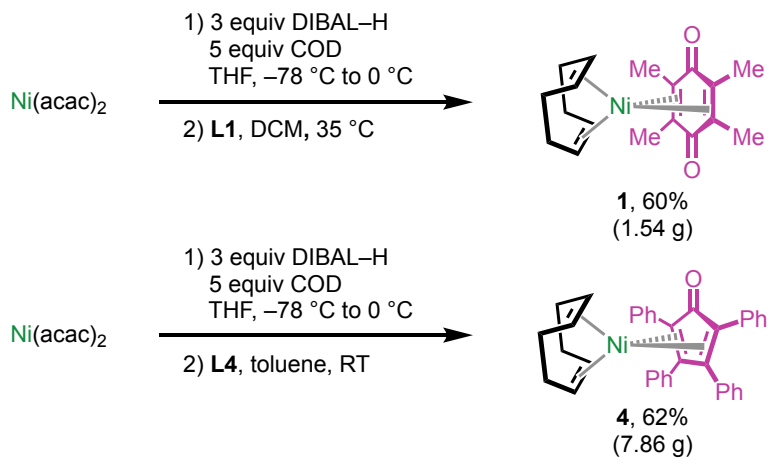

Figure 3. Synthesis of complexes $\mathbf{1}$ and $\mathbf{4}$ from nickel(II) with DIBAL-H as reductant on gram-scale. 


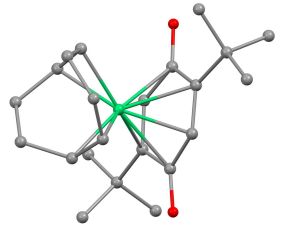

2

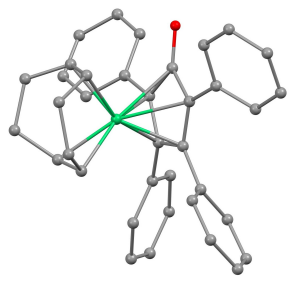

4

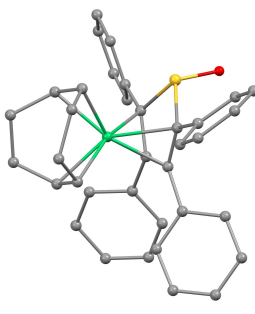

7

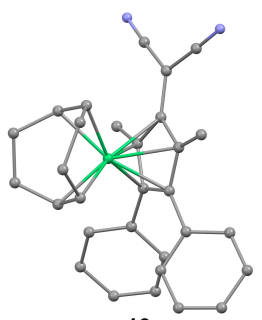

10

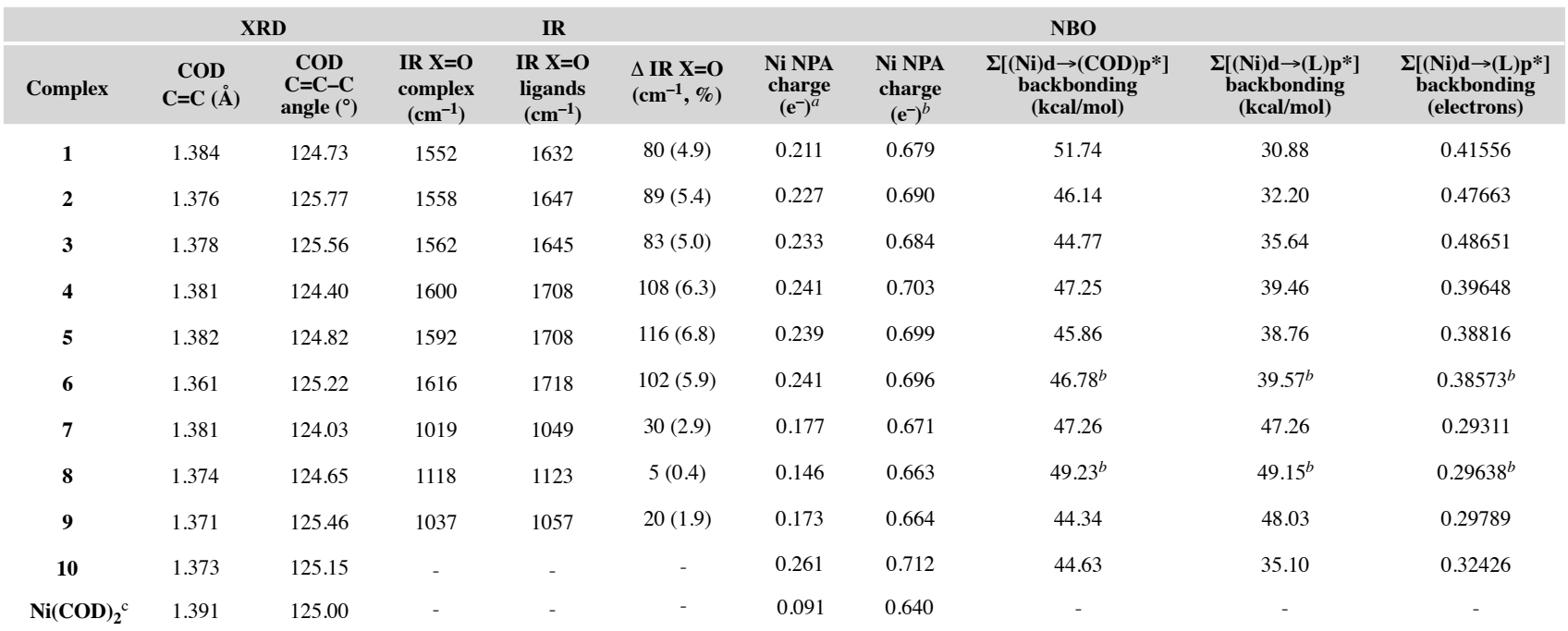

Density functional theory calculations for natural population analysis (NPA) were performed using two different version of NBO: a. NBO3, b. NBO7 (advanced unit selection available for NBO7; see SI for details), respectively. Backbonding intereactions were calculated by NBO3, unless noted, c. measured at $125 \mathrm{~K}$.

the same techniques when the data was not already available in the literature. By X-ray analysis, complexes across different ligand classes are largely isostructural in the solidstate. Common structural features of complexes 1-10 include a shared distorted tetrahedral geometry. The nickel center is coordinated to two central endocyclic olefins of the diene ligand and two olefinic moieties of COD, and the two sets of olefinic moieties in L and COD are oriented orthogonally to one another. $\sigma$-Donation from the filled carbonyl $\pi-$ orbitals to the nickel center appears to be minimal in complexes 1-6. Furthermore, in all three thiophene- $S$-oxidecontaining complexes 7-9, there is no evidence of $\sigma$-bonding from lone-pairs on sulfur or oxygen to the nickel center. In the solid-state structures, the sulfoxide $\mathrm{S}=0$ bond tilts away from the metal center, and the dihedral angle between the planar dienyl fragment and the $S=0$ bond decreases 29 $39^{\circ}$ compared to the free ligand, becoming almost perpendicular. Due to fundamental structural differences across different ligand classes, comparisons of M-to-L bond lengths and $\mathrm{C}=\mathrm{C} / \mathrm{C}=\mathrm{O} / \mathrm{S}=\mathrm{O}$ bond lengths among the entire collection of complexes are not especially meaningful. Instead, given that the $\mathrm{Ni}(\mathrm{COD})$ substructure is the only shared feature across the entire series, comparison of the average $\mathrm{C}=\mathrm{C}$ bond lengths of bound COD provides a means of comparing the back donation ability of filled nickel $d$ orbitals to the $\pi^{*}(\mathrm{C}=\mathrm{C})$ orbital of COD as a function of the 1,3-diene ligand (Table 1). Indeed, all of the complexes (1-10) exhibit shorter COD $\mathrm{C}=\mathrm{C}$ bond lengths than $\mathrm{Ni}(\mathrm{COD})_{2}(<1.391 \AA)^{3},{ }^{31}$ consistent with a more electron-poor metal center and attenuated $\pi$-back-bonding. There were no clear trends in $\mathrm{C}=\mathrm{C}-\mathrm{C}$ bond angles of the bound COD ligand across the series, suggesting that these values are not significantly influenced by the electronic character of the nickel center.
Consistent with expectations, for aryl-containing ligand frameworks, introduction of electron-withdrawing groups results in shorter $\mathrm{C}=\mathrm{C}$ bond lengths (entries $4-6$, entry 7 vs 8). Values for IR stretching frequencies of carbonyl $\mathrm{C}=0$ bonds or $\mathrm{S}=0$ bonds are also listed for each complex. Unlike benzoquinone and cyclopentadienone type ligands that show noticeable $\mathrm{X}=\mathrm{O}$ bond length elongation upon coordination to nickel, changes in $\mathrm{S}=0$ bond length are minimal, which is consistent with NBO data (vide infra) that suggests minimal interaction between the $\mathrm{S}=0$ bond and the metal center. ${ }^{32}$

Calculated natural population analysis (NPA) charges of the complexes were next considered. While this method has limitations in terms of accurately capturing the true oxidation state of the metal center, it nevertheless provides a useful readout of electronic trends across the series. The NPA charge at nickel for $\mathrm{Ni}(\mathrm{COD})_{2}$ was calculated to be 0.091 , while we found this value to be slightly higher for catalysts 1-10 (Table 1). Within this collection, cyclopentadienone bound nickel centers in 4-6 were more positively charged with NPA charges of roughly 0.24 , and thiophene-S-oxide bound nickel centers in 7-9 were the least positively charged with NPA charges of $0.15-0.18$. Quinone bound nickel centers were found to be intermediary with charges of 0.21-0.23. Fulvene catalyst $\mathbf{1 0}$ had the highest NPA charge of 0.26 .

We envisioned that the reactivities of the nickel center can be systematically tuned using ligands with disparate electronic properties. Thus, cyclic voltammetry (CV) studies of four representative nickel complexes $(\mathbf{1}, \mathbf{4}, \mathbf{7}, \mathbf{1 0})$ and their corresponding ligands were taken in an electrolyte solution of $0.1 \mathrm{M} \mathrm{TBAPF}_{6}$ in DMF at $100 \mathrm{mV} \mathrm{s}^{-1}$. 1,4-Duroquinone 

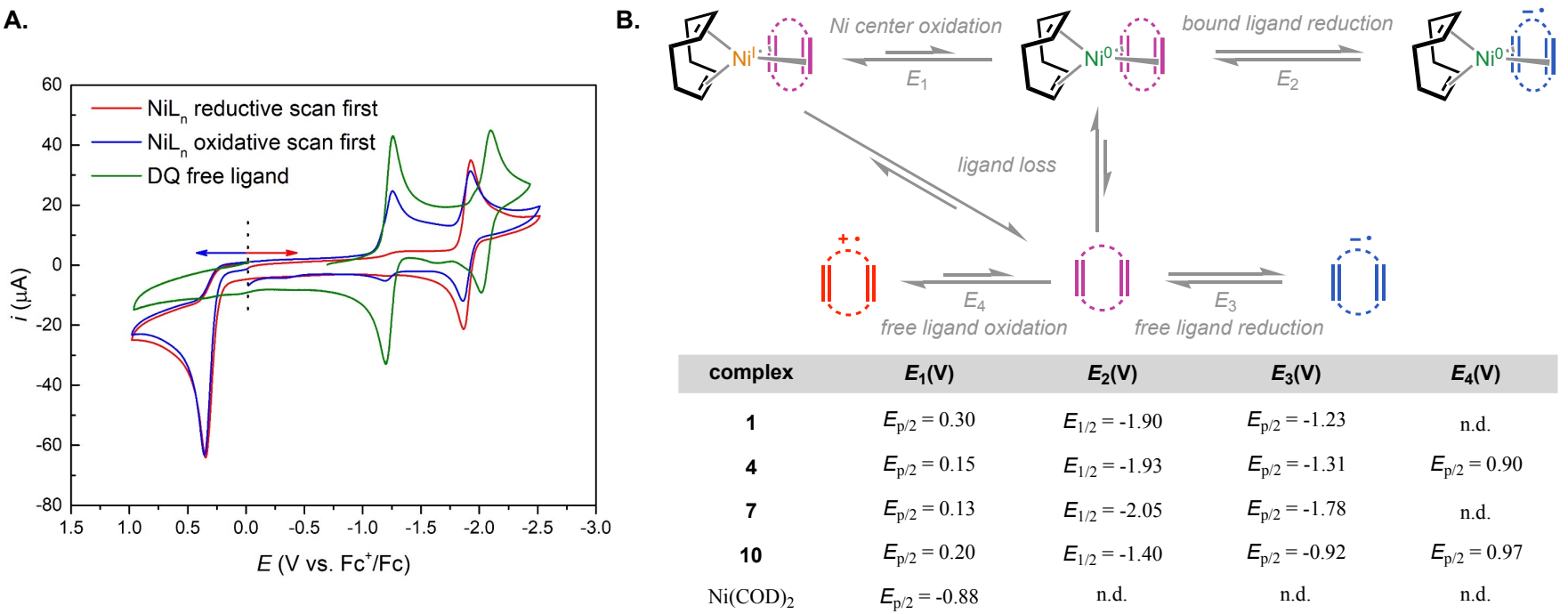

$\begin{array}{ccccc}\text { complex } & E_{1}(\mathbf{V}) & E_{2}(\mathbf{V}) & E_{3}(\mathbf{V}) & E_{4}(\mathbf{V}) \\ 1 & E_{\mathrm{p} / 2}=0.30 & E_{1 / 2}=-1.90 & E_{\mathrm{p} / 2}=-1.23 & \text { n.d. } \\ \mathbf{4} & E_{\mathrm{p} / 2}=0.15 & E_{1 / 2}=-1.93 & E_{\mathrm{p} / 2}=-1.31 & E_{\mathrm{p} / 2}=0.90 \\ \mathbf{7} & E_{\mathrm{p} / 2}=0.13 & E_{1 / 2}=-2.05 & E_{\mathrm{p} / 2}=-1.78 & \text { n.d. } \\ \mathbf{1 0} & E_{\mathrm{p} / 2}=0.20 & E_{1 / 2}=-1.40 & E_{\mathrm{p} / 2}=-0.92 & E_{\mathrm{p} / 2}=0.97 \\ \mathrm{Ni}(\mathrm{COD})_{2} & E_{\mathrm{p} / 2}=-0.88 & \text { n.d. } & \text { n.d. } & \text { n.d. }\end{array}$

Figure 4. A. Cyclic voltammograms of $\mathbf{L} 1$ (green) and complex 1 (reductive initiated scan: red, oxidative initiated scan: blue). Conditions: glassy carbon as working electrode, $\mathrm{Ag} / \mathrm{AgNO}_{3}$ reference electrode, and platinum wire as counter electrode. $2.0 \mathrm{mM}$ analyte in DMF $(0.1 \mathrm{M} \mathrm{TBAPF}$ ). Scan rate: 100 $\mathrm{mV} / \mathrm{s}$. Potentials are referred vs the $\mathrm{Fc}^{+} / \mathrm{Fc}$ couple. B. Redox properties of nickel complex. Potential values for reversible features are reported as $E_{1 / 2}$ and those for irreversible features are reported as half peak potential $E_{\mathrm{p} / 2} \cdot$ n.d. $=$ not detected.

(L1; Figure 4A) displays two reversible redox features at $1.23 \mathrm{~V}$ (all potentials calibrated $\mathrm{vs} \mathrm{Fc} / \mathrm{Fc}^{+}$) and $-2.18 \mathrm{~V}$, which are assigned to its sequential reduction to the radical anion and then the dianion, respectively. ${ }^{33}$ Notably, the voltammograms of $\mathrm{Ni}(\mathrm{COD})(\mathrm{DQ})(\mathbf{1})$ exhibit different features depending on the direction of the scan. Scanning in the reductive direction from $0 \mathrm{~V}$ results in two major redox features at $-1.87 \mathrm{~V}$ (forward scan) and $+0.30 \mathrm{~V}$ (reverse scan; Figure $4 \mathrm{~A}$, red trace). We tentatively assign the irreversible wave at $0.30 \mathrm{~V}$ to the oxidation of the nickel center [formally from $\mathrm{Ni}(0)$ to $\mathrm{Ni}(\mathrm{I})]$, and the reversible feature at $-1.90 \mathrm{~V}$ to a ligand (L1)-based single-electron reduction to a radial anion, while the nickel center maintains its formal oxidation state of $\mathrm{Ni}^{0}$. The cathodic shift $(\sim 700 \mathrm{mV})$ of ligated $1,4-\mathrm{du}-$ roquinone versus its unbound form is indicative of backbonding of the low-valent nickel to the electron-deficient quinone. In contrast, when the CV scan was initiated oxidatively, we observed a new redox feature at $-1.23 \mathrm{~V}$ (Figure $4 \mathrm{~A}$, blue trace). This quasi-reversible redox feature overlaps with the first reduction peak of free 1,4-duroquinone, suggesting that ligand dissociation takes place upon oxidation of $\mathrm{Ni}(\mathrm{COD})(\mathrm{DQ})$ at positive potentials. The irreversibility of this redox feature is likely because the reduced ligand can once again complex with $\mathrm{Ni}$. These observations suggest that ligand dissociation of DQ takes place readily when nickel is at a relatively high oxidation state, creating available coordination sites for reaction substrates.

Redox properties of complex 4, 7 and 10 are summarized in Figure 4B, which display generally similar features as complex 1 (see SI for details). We compared redox activities of these complexes with their corresponding ligands and carried out $\mathrm{CV}$ scans in both reductive and oxidative directions for each complex to probe ligand dissociation. In each case, the reductively initiated scan of the $\mathrm{Ni}$ complex is easy to interpret with fewer redox features, typically involving a ligand-based 1e-reduction and a metal-based 1e-oxidation. However, initiating the scan oxidatively results in more complex voltammograms featuring additional peaks, suggesting the formation of new species likely from oxidatively induced ligand dissociation.
Relevant physical properties of the complexes were next considered. In terms of air stability in the solid state, samples of complexes 1-10 capped under air at room temperature did not undergo any visible changes in appearance after 6 months. Similarly, there were no detectable changes in ${ }^{1} \mathrm{H}$ NMR spectra of these complexes over this period (see SI). The thermal stability in both the solid and solution states was also assayed by thermogravimetric analysis (TGA) and variable temperature (VT) NMR, respectively (Figure 5 and SI). TGA and VT NMR data illustrated a range of stability with respect to increased temperature in the solid and solution states. While duroquinone complex 1 was found to be incredibly thermally stable, with $>95 \%$ mass retained up to $200{ }^{\circ} \mathrm{C}$, Analogues 2 and $\mathbf{3}$ were less stable with $>5 \%$ mass loss observed already at $120^{\circ} \mathrm{C}$. The cyclopentadienone series (4-6) showed consistent stability by TGA, maintaining $>95 \%$ initial weight past $200{ }^{\circ} \mathrm{C}$. Thiophene-S-oxide containing complexes 7-9 demonstrated relative stability past $150{ }^{\circ} \mathrm{C}$, followed by sharp decreases in weight at points between $150{ }^{\circ} \mathrm{C}$ and $200{ }^{\circ} \mathrm{C}$. This inflection point occurred at a higher temperature for complex 9 than 7 and 8. Fulvene complex 10 maintained more than $95 \%$ of its weight past $200^{\circ} \mathrm{C}$. Data with $\mathrm{Ni}(\mathrm{COD})_{2}$ was also collected for reference. Though $\mathrm{Ni}(\mathrm{COD})_{2}$ is reported to decomposes under air at temperatures as low as $60{ }^{\circ} \mathrm{C}, 11$ in these TGA experiments where air is excluded, we found $>95 \%$ mass retention up to $140{ }^{\circ} \mathrm{C}$.

Variable temperature NMR experiments were performed for each pre-catalyst in benzene- $d_{6}$, with a temperature range of $25-60{ }^{\circ} \mathrm{C}$, covered with $5{ }^{\circ} \mathrm{C}$ increments. Complex 1 was found to be stable up to the maximum temperature examined. On the other hand, complexes $\mathbf{2}$ and $\mathbf{3}$ were found to decompose in solution past $30^{\circ} \mathrm{C}$ as indicated by significant line broadening that did not resolve upon cooling and observation of colorless precipitates. By VT NMR, cyclopentadienone complexes 4-6 were found to be exceptionally stable in solution at increased temperatures. Interestingly, these complexes exhibited coalescence of the olefinic COD protons upon heating. For complexes $\mathbf{5}$ and $\mathbf{6}$, this coalescence occurred at ca. $55{ }^{\circ} \mathrm{C}$, while for complex $\mathbf{4}$, 
A.

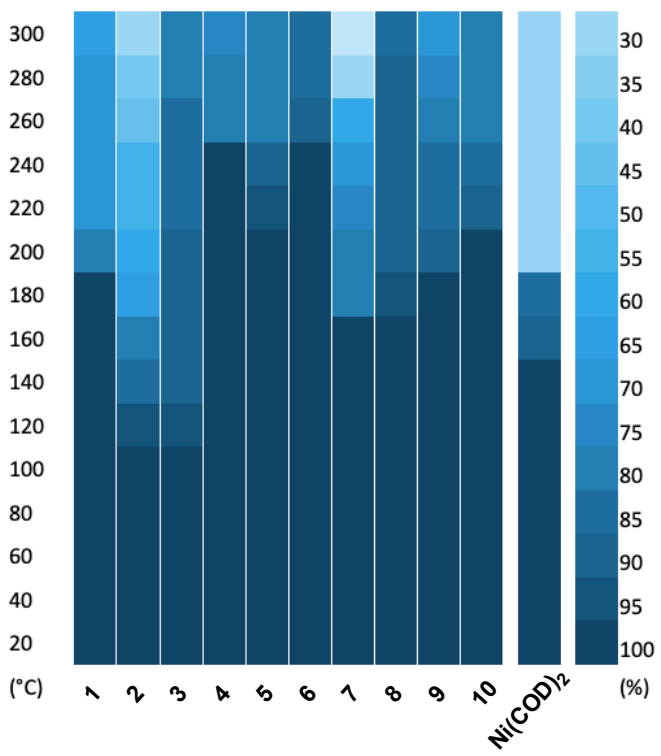

B.

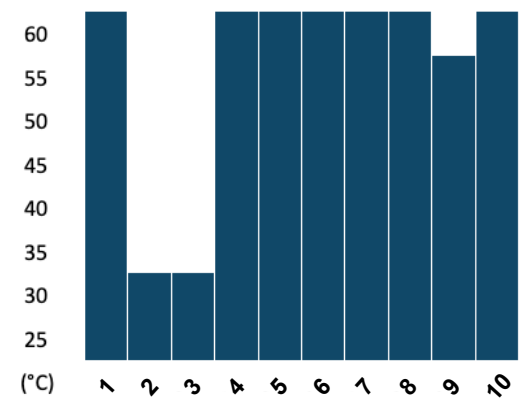

Figure 5. A. Thermal gravimetric analysis (TGA) data for complexes 1-10 taken with a range of $20-300{ }^{\circ} \mathrm{C}$ at a rate of $10{ }^{\circ} \mathrm{C}$ per minute $\left(\mathrm{N}_{2}\right.$ purge gas, platinum testing cell). Percent remaining weight (\%) as a luminescence gradient; B. Samples prepared under air with $\mathrm{C}_{6} \mathrm{D}_{6}$ as solvent under a temperature range of $25-60{ }^{\circ} \mathrm{C}$ covered with $5{ }^{\circ} \mathrm{C}$ increments. Bars indicate range of stability as indicated by lack of irreversible peak broadening.

coalescence occurred at a lower temperature of ca. $40{ }^{\circ} \mathrm{C}$, concomitant with an intriguing re-separation of these peaks at ca. $55^{\circ} \mathrm{C}$. Complexes 7-9 were also found to be mostly stable to higher temperatures in solution. Complexes 7 and 8 were found to be stable throughout our VT NMR experiments with only slight coalescence of the COD olefin peaks with increasing temperature. Complex 9 was found to be stable in solution up to $55^{\circ} \mathrm{C}$. At $60{ }^{\circ} \mathrm{C}$, significant peak broadening that did not resolve after cooling back to room temperature indicated decomposition.

\section{Evaluation of catalytic performance}

Following thorough characterization, complexes 1-10 were evaluated in terms of practical application as pre-catalysts in nickel catalysis. Prior to the development of the present extensive toolkit, we found $\mathrm{Ni}(\mathrm{COD})(\mathrm{DQ})(\mathbf{1})$ to exhibit diminished activity as a pre-catalyst relative to alternatives (e.g., $\mathrm{Ni}(\mathrm{COD})_{2}$ ) or to be inactive altogether in some reaction systems, ${ }^{16,17}$ likely due to the diminished lability of DQ. Indeed, this often occurs with low-temperature reactions and/or with weakly coordinating ligands. One of the goals of developing a broader range of nickel pre-catalysts in this toolkit was thus to afford bench stable alternatives that can replace $\mathrm{Ni}(\mathrm{COD})_{2}$ with better performance than
$\mathrm{Ni}(\mathrm{COD})$ (DQ). Thus, we initially tested the toolkit against two recently reported reactions from our labs that employ $\mathrm{Ni}(\mathrm{COD})_{2}$ as pre-catalyst: 1 ) arylamination of butenyl alcohols $^{34}$ and 2) decarboxylative cycloaddition ${ }^{35}$ (Figure 6A \& B). In nickel-catalyzed 1,2-arylamination of weakly-coordinating alkenyl alcohols (Figure 6A), we did not observe any product with Ni(COD)(DQ) (1) but were able to obtain moderate to good yields with pre-catalysts $\mathbf{2 , 3}, \mathbf{8}$, and $\mathbf{9}$. Fulvene pre-catalyst $\mathbf{1 0}$ also resulted in desired product, albeit in low yield. Not surprisingly, seemingly more inert cyclopentadienone complexes 4-6 were not active in this reaction. Thiophene-S-oxide pre-catalysts 8 and 9 performed well, while their more electron-rich counterpart 7 did not yield desired product. In the decarboxylative cycloaddition reaction (Figure 6B), we found that several complexes within the toolkit provided $\geq 95 \%$ yield after $48 \mathrm{~h}(\mathbf{1}, \mathbf{3}, \mathbf{8}, \mathbf{9})$. Reaction yield at $20 \mathrm{~h}$ provide a general idea of the comparative kinetics for these successful complexes. Ni(COD)(DQ) (1) performed well to give $65 \%$ yield after $20 \mathrm{~h}$. However, we found that thiophene- $S$-oxide complex $\mathbf{8}$ exhibited better kinetics, giving $88 \%$ after $20 \mathrm{~h}$. Cyclopentadienone complexes 4-5 and fulvene complex 10 performed poorly in this specific reaction.

In the case of nickel-catalyzed arylamination, there is stark improvement in catalytic performance with a handful of newly developed complexes $(2, \mathbf{3}, \mathbf{8}, \mathbf{9}, \mathbf{1 0})$ in contrast to previously disclosed $\mathrm{Ni}(\mathrm{COD})(\mathrm{DQ})$ (1). However, in the case of nickel-catalyzed decarboxylative cycloaddition, several candidates, including complex $\mathbf{1}$, arose as suitable pre-catalysts after extended reaction times. From this initial data, we sought a better understanding of the effect of pre-catalyst identity on reaction rates across a range of transformations. Carboxylic acid directed anti-Markovnikov hydroarylation of unactivated alkenes ${ }^{16 \mathrm{~b}}, \mathrm{C}-\mathrm{H}$ activation and alkyne annulation, ${ }^{36}$ and Suzuki coupling of aryl chlorides ${ }^{37}$ were chosen as three reactions of interest to provide examples with assorted conditions and ligands including an $\mathrm{N}, \mathrm{N}$ bidentate pyrox ligand, a monodentate phosphine ligand, and a bidentate phosphine ligand, respectively. For the first two reactions, initial rates of the reactions were measured and compared. For the Suzuki coupling, results were complicated by an induction period leading to a sigmoidal-type reaction profile. Thus, maximum rates and induction times, rather than initial rates, were measured to facilitate comparison (See SI for details and final yields for each reaction). In the alkene hydroarylation reaction, we observed quinone complexes 1-3 performing similarly despite differences in ligand substituents (Figure 6C). Cyclopentadienone complexes 4-6 had low to no catalyst activity, likely due to the strongly-coordinating nature of the cyclopentadienone scaffold that may have prevented ligand exchange to form the desired active catalyst. Only complex $\mathbf{6}$ in this class gave observable product formation at low rates compared to other catalysts. Surprisingly, complexes 7-9 varied widely 
A. Arylamination of butenyl alcohols

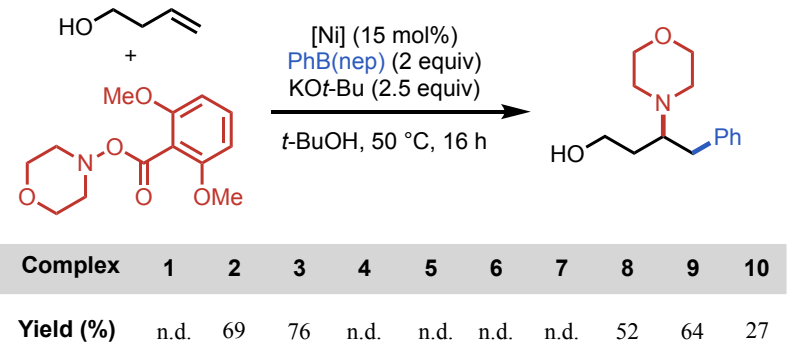

B. Decarboxylative cycloaddition

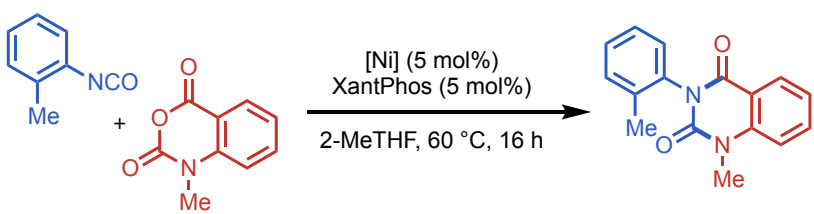

$\begin{array}{ccccccccccc}\text { Complex } & \mathbf{1} & \mathbf{2} & \mathbf{3} & \mathbf{4} & \mathbf{5} & \mathbf{6} & \mathbf{7} & \mathbf{8} & \mathbf{9} & \mathbf{1 0} \\ \begin{array}{c}\text { Yield at } \\ \mathbf{2 0} \text { h (\%) }\end{array} & 65 & 17 & 42 & \text { n.d. } & \text { n.d. } & 3 & 14 & 88 & 43 & \text { n.d. } \\ \begin{array}{c}\text { Yield at } \\ \mathbf{4 0} \text { h (\%) }\end{array} & >99 & 43 & 95 & 8 & 14 & 21 & 74 & >99 & 98 & 1\end{array}$

C. Hydroarylation of unactivated alkene<smiles>C=CCC(=O)O</smiles>

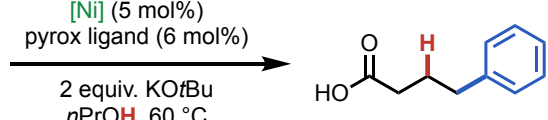

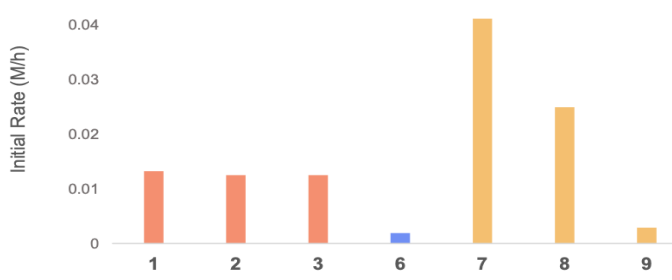

D. $\mathrm{C}-\mathrm{H}$ activation/annulation<smiles>O=C(NCc1ccccn1)c1ccccc1</smiles>

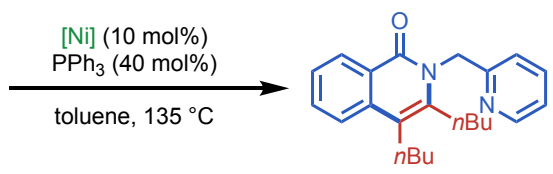

\section{E. Suzuki coupling}

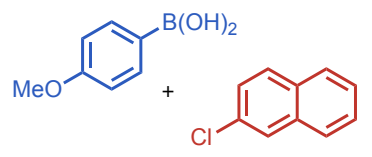

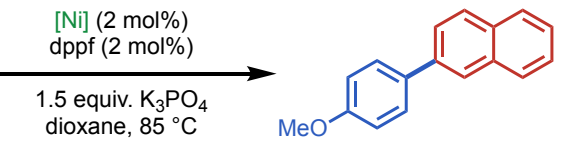

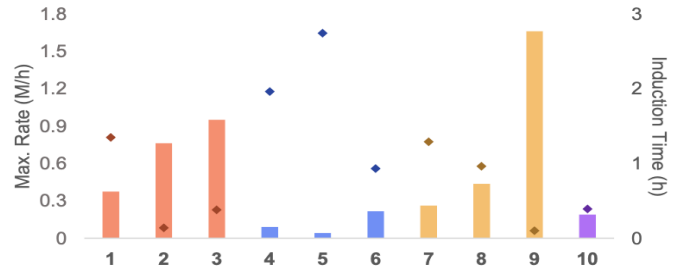

Figure 6. A, B. Yields for each catalyst in A. arylamination of butenyl alcohols (yields obtained by ${ }^{1} \mathrm{H} \mathrm{NMR}$ with $\mathrm{CH}_{2} \mathrm{Br}_{2}$ as internal standard) and $\mathrm{B}$. decarboxylative cycloaddition (yields obtained by LC based on authentic product standard); C-E. Initial rates for each catalyst in C. hydroarylation of unactivated alkenes, D. C-H activation/annulation reaction, and E. Maximum rates (solid bars) and induction times (diamonds) for each catalyst in Suzuki coupling reaction. n.d. $=$ not detected; nep $=$ neopentyl gylcolate .

in their initial rates for this reaction, with complex 7 yielding the fastest reaction rate amongst the catalysts tested. Complex $\mathbf{8}$ also resulted in rates significantly faster than that of quinone or cyclopentadienone type complexes. However, complex 9 resulted in slow product formation. These results correlate slower reaction rates with more electronwithdrawing substituents within the class of thiophene- $S$ oxide bound pre-catalysts. Lastly, fulvene complex 10 also gave no observable hydroarylation product.

Next, we applied catalysts 1-10 to a C-H activation/alkyne annulation reaction originally reported by the Chatani group (Figure 6D). ${ }^{36}$ Patterns in initial rates were observed both across classes and within each class. On average, cyclopentadienone bound 4-6 gave slightly higher rates than duroquinone bound $\mathbf{1 - 3}$, and thiophene-S-oxide bound 7-9 gave the slowest rates. Within each class, quinone bound complexes 1-3 showed slight differences in initial rate, with complexes $\mathbf{1}$ and $\mathbf{2}$ affording faster rates than $\mathbf{3}$. Within the cyclopentadienone and thiophene- $S$-oxide classes, reaction rates were positively correlated with more electron withdrawing substituents on each ligand. Data could not be collected accurately for complex $\mathbf{1 0}$ due to low yields under experimentally compatible conditions. ${ }^{38}$

Due to presence of an induction period in the Suzuki reaction, we elected to report the maximum rates (solid bars) and induction times (diamond points) rather than initial rates for comparison (Figure 6E). Complexes 1-3 lead to moderately fast rates with lower induction times, except for 1, which gave a significantly higher induction time and a lower maximum rate than the other quinone bound catalysts. Complexes 4-5 resulted in low rates with higher induction times. Here, the maximum rate was somewhat positively correlated with electron deficiency of the cyclopentadienone ligand. Maximum rates varied widely within the 
thiophene-S-oxide class of complexes, with complexes $\mathbf{7}$ and $\mathbf{8}$ giving moderate rates and complex $\mathbf{9}$ giving a very high maximum rate and a low induction time. Again, mirroring results from complexes 4-6, maximum rate was positively correlated with electron deficiency of the thiophene$S$-oxide ligand. Fulvene complex $\mathbf{1 0}$ was active in the Suzuki reaction, leading to a low maximum rate but also low induction time.

Although trends in reaction rate may exist within or among classes for each reaction, these trends do not appear to be consistent across different types of reactions. For example, trends within a class for thiophene-S-oxide complexes 7-9 are reversed when comparing the hydroarylation reaction to the $\mathrm{C}-\mathrm{H}$ activation/annulation and Suzuki reactions. Cyclopentadienone complexes 4-6 are not successful in the hydroarylation reaction and only slightly productive in the Suzuki reaction but perform competitively in $\mathrm{C}-\mathrm{H}$ activation/annulation. This range in trends and results across different reactions underscores the overarching benefits of applying a convenient toolkit of bench-stable low-valent nickel pre-catalysts toward reaction discovery and optimization.

Conclusion

By taking advantage of the favorable complexation and stabilizing nature of bidentate electron deficient olefin (EDO) ligands to form 18-electron complexes with low-valent nickel centers, our group was able to design and synthesize a varied toolkit of bench-stable nickel pre-catalysts. Numbering ten in total, this toolkit spans a range of four different EDO ligand substructures including quinones, cyclopentadienones, thiophene-S-oxides, and fulvenes. Successful complexes were characterized in detail via methods including NMR, IR, single crystal X-ray diffraction, XAS, CV, TGA, and natural bond orbital analysis. Furthermore, complex behavior was compared across three different nickel-catalyzed reactions, two of which were originally reported with $\mathrm{Ni}(\mathrm{COD})_{2}$. Diverse trends in reaction rates and induction times emphasize the necessity of extending the range of available low-valent nickel pre-catalysts to aid in reaction discovery and optimization. Ongoing efforts in our lab center upon increasing our understanding of nickel-olefin coordination chemistry and ligand exchange, as well as taking advantage of unique nickel complex properties in reaction design.

\section{ASSOCIATED CONTENT}

\section{Supporting Information}

\section{Supporting Information.}

The Supporting Information is available free of charge at https://pubs.acs.org/doi/...

Experimental procedures, spectral and crystallographic data (PDF)

NMR data (MNova format) (ZIP)

- Accession Codes CCDC 2099998 (2), 2033854 (3), 2015597 (4), 2033179 (5), 2015096 (6), 2015598 (7), 2033832 (8), 2025093 (9), 2049811
(10), 2049810 (L3), 2100570 (L5), 2100569 (L6), 2019514 (L7), 2019515 (L8), 2035558 (L9), 2015097 (SL1), 2020674 (SL2), 2129338 (L18), 2129337 (L19), 2129336 (L20), and 2129339 (SL3) contain the supplementary crystallographic data for this paper. These data can be obtained free of charge via www.ccdc.cam.ac.uk/data request/cif, or by emailing data request@ccdc.cam.ac.uk, or by contacting The Cambridge Crystallographic Data Centre, 12 Union Road, Cambridge CB2 1EZ, UK; fax: +44 1223336033.

\section{AUTHOR INFORMATION}

\author{
Corresponding Author \\ *keary@scripps.edu
}

\section{Author Contributions}

§These authors contributed equally.

\section{ACKNOWLEDGMENT}

Financial support was provided by Bristol Myers Squibb, the National Science Foundation (CHE-2102550), and the National Institutes of Health (R01GM130928). We further thank the Schimmel Family Endowed Fellowship Fund for a Graduate Fellowship (C.Z.R.), the Kwanjeong Educational Foundation for a Graduate Fellowship (T.K.), and Bristol Myers Squibb for a Graduate Fellowship (Z.-Q. L.). We thank Dr. Michael A. Schmidt (BMS), Dr. Samantha N. MacMillan (Cornell), and Prof. Kyle M. Lancaster (Cornell) for helpful discussion. Denis Har, Dr. Shulin $\mathrm{Wu}$, and Dr. Candice Joe (BMS) are acknowledged for assistance with ligand and catalyst synthesis.

\section{REFERENCES}

1) Ananikov, V.P. Nickel: The "Spirited Horse" of Transition Metal Catalysis. ACS Catal. 2015, 5, 1964-1971.

2) Tasker, S. Z.; Standley, E. A.; Jamison, T. F. Recent Advances in Homogeneous Nickel Catalysis. Nature 2014, 509, 299-309.

3) Diccianni, J. B.; Diao, T. Mechanisms of Nickel-Catalyzed Cross-Coupling Reactions. Trends Chem. 2019, 1, 830844.

4) Ludwig, J. R.; Schindler, C. S. Catalyst: Sustainable Catalysis. Chem 2017, 2, 313-316.

5) Holland, P. L. Reaction: Opportunities for Sustainable Catalysts. Chem 2017, 2, 443-444.

6) Bullock, R. M. Reaction: Earth-Abundant Metal Catalysts for Energy Conversions. Chem 2017, 2, 444-447.

7) Hazari, N.; Melvin, P. R.; Beromi, M. M. Well-defined Nickel and Palladium Precatalysts for Cross-coupling. Nat. Rev. Chem. 2017, 1, 0025.

8) Nett, A. J.; Cañellas, S.; Higuchi, Y.; Robo, M. T.; Kochkodan, J. M.; Haynes, M. T., II; Kampf, J. W.; Montgomery, J. Stable, Well-Defined Nickel(0) Catalysts for Catalytic C$\mathrm{C}$ and C-N Bond Formation. ACS Catal. 2018, 8, 66066611.

9) Wilke, G. Contributions to Organo-Nickel Chemistry. Angew. Chem. Int. Ed. 1988, 27, 185-206.

10) Schunn, R. A.; Ittel, S. D.; Cushing, M. A.; Baker, R.; Gilbert, R. J.; Madden, D. P. Bis(1,5-Cyclooctadiene)Nickel(0). In org. Synth. 1990, 28, 94-98.

11) Wender, P. A.; Smith, T. E.; Duong, H. A.; Louie, J.; Standley, E. A.; Tasker, S. Z. Bis(1,5-cyclooctadiene)nickel(0). In Encyclopedia of Reagents for Organic Synthesis; Wiley, 
2015, https://doi.org/10.1002/047084289X.rb118.pub3.

12) For benchtop-stable $\mathrm{Ni}(\mathrm{COD})_{2}$ using paraffin capsules, see: a) Dander, J. E.; Weires, N. A.; Garg, N. K. Benchtop Delivery of $\mathrm{Ni}(\mathrm{cod})_{2}$ using Paraffin Capsules. Org. Lett. 2016, 18, 3934-3936. b) Mehta, M. M.; Boit, T. B.; Dander, J. E.; Garg, N. K. Ni-Catalyzed Suzuki-Miyaura Cross-Coupling of Aliphatic Amides on the Benchtop. Org. Lett. 2020, 22, 1-5.

13) Tran, V. T.; Li, Z.-Q.; Apolinar, O.; Derosa, J.; Joannou, M. V.; Wisniewski, S. R.; Eastgate, M. D.; Engle, K. M. $\mathrm{Ni}(\mathrm{COD})(\mathrm{DQ}):$ An Air-Stable 18-Electron Nickel(0)-Olefin Precatalyst. Angew. Chem. Int. Ed. 2020, 59, 74097413.

14) Schrauzer, G. N.; Thyret, H. Novel "Sandwich" Compounds of Nickel(0); Duroquinone-nickel(0) Complexes with Cyclic Dienes. Z. Naturforsch. 1962, 17b, 73-76.

15) For selected examples of Ni(COD)(DQ) use in subsequent literature, see: (a) Jang, Y.; Lindsay, V. N. G. Synthesis of Cyclopentenones with Reverse Pauson-Khand Regiocontrol via Ni-Catalyzed C-C Activation of Cyclopropanone. Organic Letters 2020 22, 8872-8876. (b) Reilly, S. W.; Lam, Y.; Ren, S.; Strotman, N. A. Late-Stage Carbon Isotope Exchange of Aryl Nitriles through Ni-Catalyzed C-CN Bond Activation. J. Am. Chem. Soc. 2021, 143, 4817-4823. (c) Cho, I. Y.; Kim, W. G.; Jeon, J. H.; Lee, J. W.; Seo, J. K.; Seo, J.; Hong, S. Y. Nickelocene as an Air- and Moisture-Tolerant Precatalyst in the Regioselective Synthesis of Multisubstituted Pyridines. J. Org. Chem. 2021, 86, 9328-9343.

16) (a) Marchese, A. D.; Wollenburg, M.; Mirabi, B.; AbelSnape, X.; Whyte, A.; Glorius, F.; Lautens, M. Nickel-Catalyzed Enantioselective Carbamoyl Iodination: A Surrogate for Carbamoyl Iodides. ACS Catal. 2020, 10, 47804785. (b) Li, Z.-Q.; Fu, Y.; Deng, R.; Tran, V. T.; Gao, Y.; Liu, P.; Engle, K. M. Ligand-Controlled Regiodivergence in Nickel-Catalyzed Hydroarylation and Hydroalkenylation of Alkenyl Carboxylic Acids Angew. Chem. Int. Ed. 2020, 59, 23306-23312. (c) Marchese, A. D.; Adrianov, T.; Köllen, M. F.; Mirabi, B.; Lautens, M. Synthesis of Carbocyclic Compounds via a Nickel-Catalyzed Carboiodination Reaction. ACS Catal. 2021, 11, 925-931. (d) Zheng, Y.-L.; Xie, P.-P.; Daneshfar, O.; Houk, K. N.; Hong, X.; Newman, S. G. Direct Synthesis of Ketones from Methyl Esters by Nickel-Catalyzed Suzuki-Miyaura Coupling. Angew. Chem. Int. Ed. 2021, 60, 13476-13483.

17) Apolinar, O.; Tran, V. T.; Kim, N.; Schmidt, M. A.; Derosa, J.; Engle, K. M. Sulfonamide Directivity Enables Ni-Catalyzed 1,2-Diarylation of Diverse Alkenyl Amines. ACS Catal. 2020, 10, 14234-14239.

18) Nattmann, L.; Saeb, R.; Nöthling, N.; Cornella, J. An AirStable Binary Ni(0)-Olefin Catalyst. Nat. Catal. 2020, 3, 6-13.

19) Nattmann, L.; Cornella, J. Ni(4-tBustb) 3 : A Robust 16-Electron $\mathrm{Ni}(0)$ Olefin Complex for Catalysis. Organometallics 2020, 39, 3295-3300.

20) In cases where marginal amounts of conversion to $\mathrm{Ni}(\mathrm{COD})(\mathrm{L})$ was observed in $\mathrm{C}_{6} \mathrm{D}_{6}$, additional experiments were conducted in relatively more polar aprotic solvent than $\mathrm{C}_{6} \mathrm{D}_{6}$, such as toluene- $\mathrm{d}_{8}, \mathrm{CD}_{2} \mathrm{Cl}_{2}$, acetone- $\mathrm{d}_{6}$. However, no additional ligand was found to be successful through this process.

21) Physical appearance of unsuccessful complexation includes heterogeneous mixture with various colors, such as black, brown, orange, yellow, purple, and often accompanied decomposition of nickel, indicated by nickel black or nickel mirror formation.
22) Jain, R.; Kabir, K.; Gilroy, J. B.; Mitchell, K. A. R.; Wong, K.; Hicks, R. G. High-Temperature Metal-Organic Magnets. Nature 2007, 445, 291-294.

23) Huynh, M. T.; Anson, C. W.; Cavell, A. C.; Stahl, S. S. Quinone $1 \mathrm{e}^{-}$and $2 \mathrm{e}^{-} / 2 \mathrm{H}^{+}$Reduction Potentials: Identification and Analysis of Deviations from Systematic Scaling Relationships. J. Am. Chem. Soc. 2016, 138, 1590315910.

24) Johnson, J. B.; Rovis, T. More Than Bystanders: The Effect of Olefins on Transition-Metal-Catalyzed Cross-Coupling Reactions. Angew. Chem. Int. Ed. 2008, 47, 840-871.

25) Defieber, C.; Grützmacher, H.; Carreira, E. M. Chiral Olefins as Steering Ligands in Asymmetric Catalysis. Angew. Chem. Int. Ed. 2008, 47, 4482-4502.

26) Eastgate, M. D.; Guono, F. G. Mechanistic Insight into the Palladium-Catalyzed 1,4-Oxidation of 1,3-Dienes to 1,4Dicarboxy-alk-2-enes. Angew. Chem. Int. Ed. 2009, 48, 5958-5961.

27) Eisch, J. J.; Galle, J. E.; Aradi, A. A.; Boleslawski, M. P. Organic Chemistry or Subvalent Transition Metal Complexes XI. Oxidative Addition of Nickel(0) Complexes to Carbon-Carbon Bonds in Alkynes: Nickelirenes and Nickeloles as Catalytic Carriers in the Oligomerization of Alkynes. J. Organomet. Chem. 1986, 312, 399-416.

28) Albrecht, R.; Weiss, E. Thiophendioxide und ihre Eisencarbonyl-Komplexe. J. Organomet. Chem. 1990, 399, 163-188.

29) Albrecht, R.; Weiss, E. Thiophendioxid-Komplexe des Cobalts. J. Organomet. Chem. 1991, 413, 355-377.

30) Edelmann, F.; Lubke, B.; Behrens, U. ÜbergangsmetallFulven-Komplexe, XVIII. Über (Fulven)nickel(0)-Komplexe. Strukturvergleich von (1,5-Cyclooctadien)(6,6-diphenylfulven)nickel und Tricarbonyl-(6,6-diphenylfulven)eisen. Chem. Ber. 1982, 115, 1325-1331.

31) Macchi, P.; Proserpio, D. M.; Sironi, A. Experimental Electron Density Studies for Investigating the Metal $\pi$-Ligand Bond: the Case of Bis(1,5-cyclooctadiene)nickel. J. Am. Chem. Soc. 1998, 120, 1447-1455,

32) Kim, C. K.; Lee, K. A; Kim, C. K.; Lee, B.-S.; Lee, H. W. NBO Analyses of the Back-Bonding in Metal-Olefin Complexes. Chem. Phys. Lett. 2004, 391, 321-324.

33) Rieke, R. D.; Saji, T.; Kujundzic, N. Electrochemical studies of methyl substituted 1,4-quinones: Part I. The electrochemical dimerization of duroquinone. J. Electroanal. Chem. 1979, 102, 397-405.

34) Kang, T.; Kim, N.; Cheng, P. T.; Zhang, H.; Foo, K.; Engle, K. M. Nickel-Catalyzed 1,2-Carboamination of Alkenyl Alcohols, J. Am. Chem. Soc. 2021, 143, 13962-13970.

35) Beutner, G. L.; Hsiao, Y.; Razler, T.; Simmons, E. M.; Wertjes, W. Nickel-Catalyzed Synthesis of Quinazolinediones. Org. Lett. 2017, 19, 1052-1055.

36) Shiota, H.; Ano, Y.; Aihara, Y.; Fukumoto, Y.; Chatani, N. Nickel-Catalyzed Chelation-Assisted Transformations Involving Ortho $\mathrm{C}-\mathrm{H}$ Bond Activation: Regioselective Oxidative Cycloaddition of Aromatic Amides to Alkynes. J. Am. Chem. Soc. 2011, 133, 14952-14955.

37) Ge, S.; Hartwig, J. F. Highly Reactive, Single-Component Nickel Catalyst Precursor for Suzuki-Miyuara CrossCoupling of Heteroaryl Boronic Acids with Heteroaryl Halides. Angew. Chem. Int. Ed. 2012, 51, 12837-12841.

38) Complex 10 gave $30 \%$ yield at $135{ }^{\circ} \mathrm{C}$, which was necessary for kinetics data acquisition. Using conditions from the original report by Chatani and coworkers (Ref. 35), complex 10 gave $86 \%$ yield at $170{ }^{\circ} \mathrm{C}$. Yields were obtained by crude ${ }^{1} \mathrm{H}$ NMR with $\mathrm{CH}_{2} \mathrm{Br}_{2}$ as internal standard. See SI for further details. 